\title{
Design and Implementation of Business Process Management Curriculum: A Case in Dutch Higher Education
}

\author{
Pascal Ravesteyn and Johan Versendaal \\ HU University of Applied Sciences Utrecht, Nijenoord 1, 3552 AS, Utrecht, NL \\ \{pascal.ravesteijn, johan.versendaal\} ahu.nl \\ Utrecht University, Padualaan 14, 3583 CH, Utrecht, NL \\ \{pascalr, j.versendaal\}@cs.uu.nl
}

\begin{abstract}
This paper describes a joint effort by two educational and scientific institutes, the HU University of Applied Sciences and Utrecht University, in designing a BPM course that not only transfers theoretical knowledge but lets students also experience real life BPM-systems and implementation issues. We also describe the implementation of the developed module with an indication of its success: it is now running for the fifth time, and although there continue to be points for improvement, over the years several scientific papers in the BPM domain resulted from the course, as well as a reasonable amount of students started their final thesis project in the BPM-domain.
\end{abstract}

Keywords: BPM, education, design, implementation.

\section{Introduction}

The adoption of Information Technology (IT) by organizations has grown tremendously in the last fifty years. During this period the focus of how IT is used has gradually changed from computational support to using IT as a means to realize more effective and efficient processes. One of the trends that have caused this change is the rapidly growing globalization in which organizations collaborate within and across supply chains around the world. Traditional IT support for these types of collaboration is expensive and the implementation of customized solutions does not live up to expectations [1]. Consequently one of the domains receiving increased attention is that of Business Process Management. BPM can be considered a 'holistic' management approach that enables process orientation and improvement within organizations and aims at more flexible processes and information systems, thereby making organizations more agile [2]. Based on the service-oriented architecture (SOA) paradigm BPM-systems enable analyses, modeling, execution and improvement of an organizations public and private processes thereby extending the usability of legacy systems and increasing the flexibility of processes [2, 3].

The change towards process orientation in organizations requires a cross-functional perspective on processes and customers instead of a focus on hierarchy and functions [4] and therefore emphasis has shifted from functional specialization towards 
processes [5]. If we review the information systems curricula at Universities we notice that there is a growing attention for modules with a clear emphasis on business process analyses and automation. The importance of cross-functional integration and business process orientation has also been notified in the domain of business education; however, shortcomings in existing curricula are still there [4].

This paper addresses the topic of BPM competencies in University education and provides an example on how to set up a process oriented curriculum, based on four years of experiences by two Dutch Universities that established a joint BPM course for both fulltime and part-time undergraduate and graduate students.

In the following section we describe related work on process oriented education modules. The third section describes the course design and content. The fourth section will relate the outcomes and the experiences of the students together with the lessons learned. In the final and fifth section we present some conclusions and suggestions for further improvements to the course.

\section{Related Work}

As a start to this research, a study was conducted to find best-practices of other universities about the development of a BPM course [6]. However despite the amount of research available on BPM there were was little in-depth information available on curricula that specifically addressed training in skills and competencies in BPM.

Fingar [7] stated that the curricula of MBA-courses at business schools are too focused on administrative skills and hardly pay any attention to (process) innovation. He suggests a curriculum in which a core of MBA topics (such as finance and accounting, quantitative analysis, economics, marketing and organizational behaviour) is integrated with modules that teach skills in business process management, business activity monitoring, process modeling, process improvement and simulation.

In Bandare et al. [8] a study is described that determines whether there is a large demand for business process modeling skills. For this 300 online job vacancies that explicitly mentioned process modeling skills were analyzed. Subsequently she organized a focus group representing potential BPM recruiters to validate and contextualize the findings. It should be noted however, that this study was focused on business process modeling skills and not the broader set of competencies needed in business process management projects.

Zur Meuhlen [9] reveals a more detailed view on the skills that are needed in BPM efforts. He distinguishes four different groups that are involved in BPM-projects: (1) executives, (2) business analysts, (3) systems analysts, and (4) vendors or systems integrators. Each group has different responsibilities and therefore needs a differentiated set of skills. For example, executives need to ensure process performance and compliance, and hence need skills in process analysis, governance and portfolio management. In contrast systems analysts are responsible for the implementation of the process and its corresponding information systems and therefore need skills in process modeling, workflow implementation, user interface design and systems integration. In his paper Zur Meuhlen does not only provide insight in BPM skills, he also presents a preliminary list of universities that offer BPM programs. 
While the papers mentioned above are interesting none of them describe how to develop a curriculum in BPM or experiences in teaching. The only paper that does focus on the development process is by Recker and Rosemann [10]. They explain in detail the setup, structure, and experiences of a course in business process modeling at the Queensland University of Technology in Australia. However the topic is on business process modeling and does not include management: the paper merely provides insights in how to develop a process oriented curriculum and which teaching techniques can be used.

Because the amount of literature on education in BPM is sparse we decided to include literature on Enterprise Resource Planning (ERP) course design. Systems for ERP as well as systems for BPM are both enterprise information systems dealing with cross-functional processes. ERP systems generally contain several sorts of workflow processes, which are made explicit in BPM systems. We found that most of the ERP education development is based on one of the following four categories of approaches [11, 12]:

1. ERP training;

2. ERP and business processes;

3. Information Systems approach;

4. Selection and implementation concepts.

The first approach is basically instruction or training in a specific ERP system. This is very similar to the training courses that the ERP and also BPM-systems developers and suppliers provide to their customers and could be done by reusing commercial training material. The second approach focuses on business processes and related concepts (e.g. financial administration or production scheduling and planning) and uses ERP to assist in the presentation and clarification of these methods and concepts. For this approach, commercial training material is not sufficient; and new material will have to be developed. The third approach uses ERP to illustrate information systems concepts. It is very similar to the second approach; only the target group or goal differs. Instead of teaching business students and business concepts, the target group will most likely be computer science / information systems students and the concepts that are taught are different. The last approach is to teach about ERP related skills, such as selection and implementation of ERP software. It is not really necessary to use a real live ERP system for this although it could give a clearer picture of the complexity of such systems. Of course, it is also possible to combine aspects of all approaches to create a more hybrid approach.

Typically in the course we aimed to develop we wanted to use a BPM-system in support and clarification to the theory. Furthermore in teaching BPM it is important to realize that not only process related knowledge and skills are essential, we also want students to have a high degree of self-awareness, be able to think critical and keep on learning continuously. In the field of BPM, particularly, it is becoming increasingly important to also understand aspects of the development, implementation and maintenance of e-business solutions due to the continuing evolution of BPM [13]. Therefore any course on BPM should in our opinion consist of three parts 1) theory and methods from a business perspective 2) theory and methods from a technical perspective and 3) a practical part that integrates the former two via lifelike exercises and confronts the student with state-of-the-art software. 


\section{Course Design}

To teach students all three aspects of BPM as defined in section 2, five years ago the HU University of Applied Sciences together with the Utrecht University developed a course that can be followed by both Master and Bachelor students simultaneously. The course was designed with two tracks that complement each other. The first track consists of theory on BPM from both the business and technical perspectives. Each week during a three hour period we first discuss scientific theory, methods and techniques, that is then followed by a guest lecture in which practical examples are discussed in relation to the theory of the first half of the period. The second track is entirely based on a case study that we developed in which the students have to analyze, improve, implement and execute the processes in a supply chain. For this again a three hour time period is reserved. The entire course now runs for 9 weeks and is followed by presentations in week 10. Students that follow and finish the course are awarded 7.5 ECTS (European Credits) which means that the total time spent on this course should amount to 210 hours. So besides the 54 hours of classes (both theory and practical) students should spend a total of 156 hours on self study. This time should be spent for about $50 \%$ on theoretical assignments and $50 \%$ on the practical assignment. Grading of the course consists of a 50\% judgment of the digestion of the theoretical part, and a $50 \%$ judgment of the practical work.

An innovative feature of the course is that we purposely combine students from bachelor level (who follow a computer science course at the HU University of Applied Sciences) with students from a masters level (from the master business informatics of the Utrecht University). This combination means that students who follow practical orientated education and tend to be very pragmatic have to work together with students that do a scientific education and have a more analytical and critical perspective. Yet, while the students have different levels of education (which in practice will be very normal during a BPM project), it does not mean that one group is better than the other. Typically the master students will take the lead in the theoretical scientific track while the bachelor students are better equipped to manage the practical track. Because we purposely combine the students into groups for their assignments they must work together. This also helps us partly to simulate the business (master business informatics) versus IT (bachelor computer science) divide which students will encounter in practice. Furthermore we let the students experience one of the most important aspects of BPM, the fact that they will need to be able to work with persons from different disciplines and with different perspectives.

An overview of the course is given in figure 1 and in the following two subsections both the theoretical and the practical track will be explained in more detail.

\subsection{Theoretical Track}

During the theoretical track students are presented with a wide range of topics related to BPM from both a business and IT perspective. Furthermore students (in teams of two) have to perform research and write a paper, for which the literature and state-ofthe-art of BPM research and practice as presented in the lectures of the theoretical track can be used. Each year we present students with one or more topics from which 


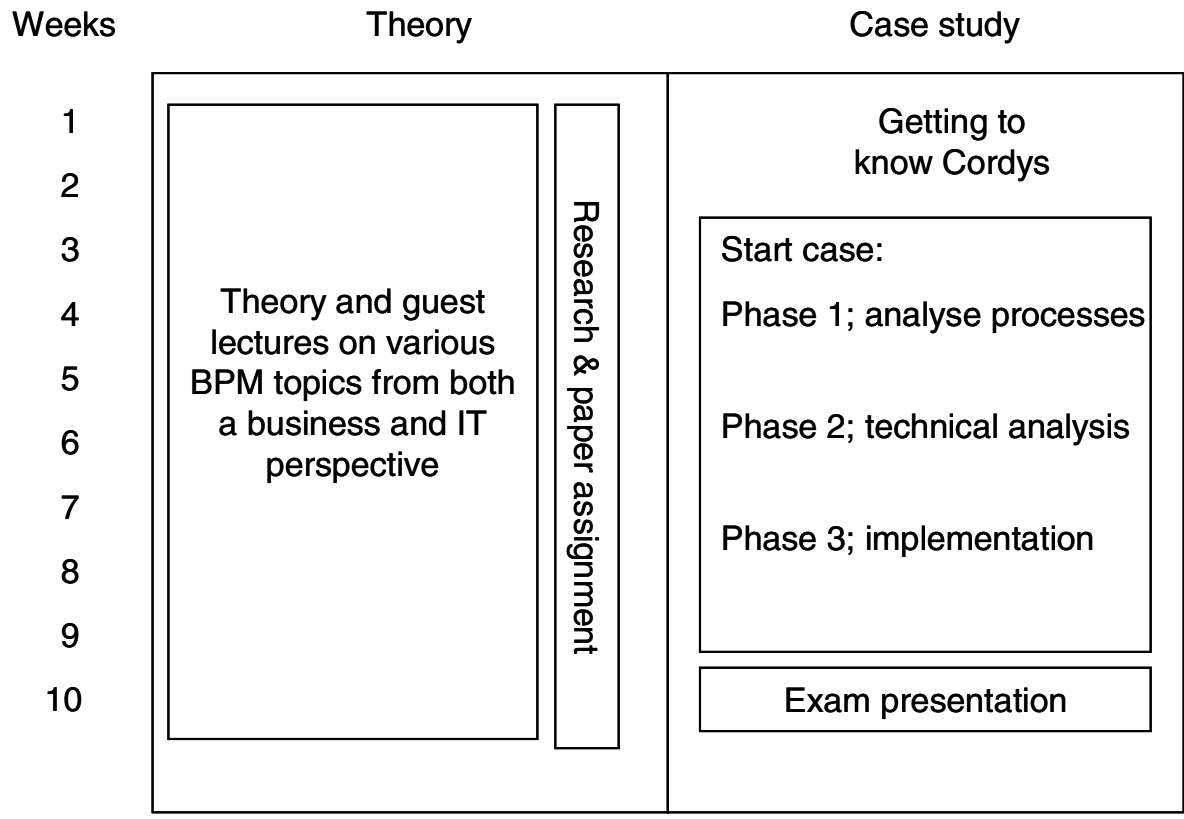

Fig. 1. Course overview

they can choose to write their paper; some of the topics in the past were: BPMsystems implementation, human interaction management, BPM-mashups, ERP and $\mathrm{BPM}$, and business rules management in relation to BPM.

In the lectures, more or less the following topics are covered:

- $\quad$ BPM basics from a business perspective; business process management can provide organizations with the ability to save money and time. The role processes play within an enterprise, to stay competitive and remain agile in the changing global market place is highlighted.

- BPM-systems implementation; the aim of this unit is to introduce the student to the general concepts of business process management systems (BPMS). In short we cover the history of BPM-systems, its characteristics and architecture, give an overview of the providers of BPMSs etc.

- BPM standards, methods and techniques are introduced. We focus on the role of standards (modeling, information, quality, and IT). Maturity models and business and IT alignment are discussed. Also the importance of quality management methods and techniques are covered.

- Business Process Modeling. An overview of different techniques to model, analyze and improve processes is given. Furthermore the Business Process Modeling Notation and its execution language (BPEL) are taught and practiced.

- $\quad$ Service Oriented Architecture (SOA) in relation to BPM. The synergy and differences between BPM and SOA are presented. The SOA paradigm is 
explained together with the business drivers for SOA. Important SOA concepts like loose-coupling, service granularity, service contracts, integration and enterprise service bus, governance and security. Also SOA standards and strategies for deploying SOA are discussed.

- $\quad B P M(S)$ Implementation. Here we take the students from process design through implementation to the management of processes and their supporting information systems. Students learn the distinction between business processes and business rules and how they can be implemented in information systems.

- Human Interaction Management / Dynamic BPM. While most current BPM efforts are focused on well structured processes there are also many ad-hoc activities and non-structured processes that need managing and control. The consequences of the fast increasing amount of knowledge workers and a changing way of working (place and time independent) are discussed together with the methods and tools to support these types of activities and processes.

- $\quad$ BPM and performance measurement. Here we cover the essentials of Business Intelligence (origins and drivers, major characteristics, implementation aspects, lifecycle etc.). Other important aspects that are covered are: BI strategy, business process monitoring and control, business and technical requirements for a BI architecture and the difference between BI and business activity monitoring (BAM).

Besides covering each of these topics in theoretical lectures we also invite companies to come and present their perspective and experiences. Invitations are sent to three different categories of companies a) consultancy organizations b) software developers (BPM system vendors) and c) end user organizations. In this way students obtain an overview of the different perspectives on BPM related issues. Organizations that have participated in the course are amongst others: BEA/Oracle (software developer), ASR/Fortis (end user in the financial sector), Capgemini (consultancy), Cordys (software developer), O\&I (management consultancy), SNS/Reaal (end user in the financial sector), and PriceWaterhouseCoopers (consultancy). Furthermore during the last three years the chairman of the Dutch BPM-Forum (Frits Bussemaker) gave a guest lecture at the start of the course.

The grading of the theoretical part is solely based on the quality of the research paper that students need to write in teams of two. In the paper it should be easily verifiable to what degree the students were able to include and process the theory and practical lessons from the (guest) lectures.

\subsection{Practical Track}

The practical part of the course is developed in such a way that students are able to attain knowledge and skills in three categories of competencies related to BPM, labeled: 'business administration', 'information architecture and technology' and 'influence and alignment'.

The first group of competencies states students should be able to recognize and understand the relations between the various functions and departments in an organization 
and between organizations. Furthermore they should be able to identify relevant market developments for the organization and to propose process improvements and/or implementation of ICT applications as a response to these developments. Finally they should be able to identify and to model company processes and interactions within and between organizations. The second group of competencies are more technical and students that master them are 1) able to design a system architecture for collaboration in extended enterprises in which new ICT capabilities are used 2) understand the basics of SOA and BPM-systems, and 3) are able to install and configure BPM-systems and use them to integrate different information systems within an organization and across its supply chain. The final group of competencies is very much aimed at communicative skills. Within BPM projects students should 1) be able to be conversant with both the domains of business and ICT within the organization 2) be able to communicate with all organizational layers on a clear and effective way about investments, business and ICT innovations in terms of business issues and benefits 3 ) be able to reflect on their own choices and activities and to indicate their own skills, and 4) be able to apply the set of conversational techniques and competences in order to achieve effective communication in interviews and presentations.

To let students acquire the complete set of competencies a case study is developed in which students are challenged to improve processes across a supply chain. This chain consists of three organizations that collaborate with each other: a Retailer, a Wholesaler and a Manufacturer (see figure 2). Students are divided into teams of two and then assigned to one organization in the supply chain. Each supply chain therefore consists of at least six students. Depending on the number of students in the course more instances of supply chains are formed.

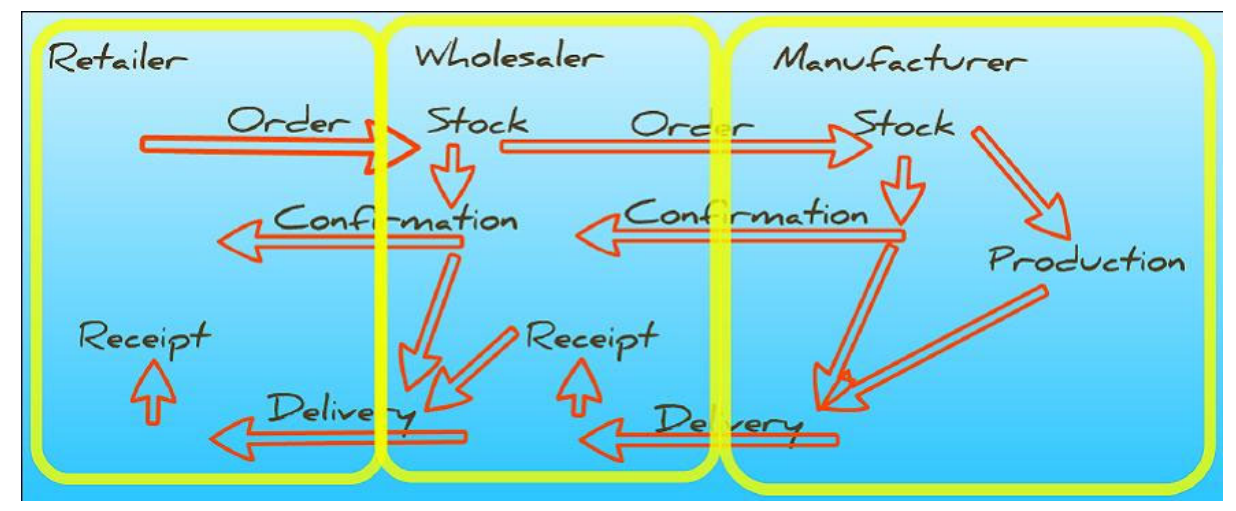

Fig. 2. An overview of the supply chain processes in the case study

The supply chain case consists of a wholesaler offering bicycles to retailers. If the retailer wants to buy from this specific wholesaler, he currently has to make a phone call or sent an email. However the students should develop a purchase application that the retailer can use to connect to the wholesalers system. This application should make use of the existing information systems and needs to be completely based on web services. To fulfill the orders of the retailer, the wholesaler has to manage stock 
levels in his warehouse system. When an item in stock falls below a certain threshold, the wholesaler must restock the item by ordering this at the manufacturer. In order to comply with the wholesaler's request, the manufacturer may have to execute a production run to build the finished goods. Again these processes are only automated within the boundaries of the respective organizations. It is the task of the students to analyze and improve these processes and then implement and execute them by using a particular BPM-system (in our course we use Cordys BOP 4 [14]).

During this case study students will have to go through several phases (similar to those of a real life BPM-systems implementation project) to be able to develop a good supply chain solution. During the first phase students need to create a clear picture of both the processes within the organization that they are assigned and of the interaction between the business partners in the supply chain and their own internal processes. Thereby they learn the difference between processes which will be kept internal or private to the organization and those that will be shared with partners in the supply chain, also called public processes. Together the organizations within a supply chain must agree on a process architecture for the whole supply-chain. Furthermore a set of appropriate key performance indicators for monitoring the supply chain should be determined. Performance indicators can be formulated on the activity-, business- or supply chain levels. During this phase the models are descriptive only but they should be modeled using the features available through the Cordys system. At the end of this phase (typically two to three weeks) a functional design should be handed over to the lecturer for control purposes.

In the second phase students have to identify, per organization in the supply chain, which information will be required from the other business partners and accordingly which web services have to be developed. The information that is delivered and used by the web services is deducted from the process analysis done in the first phase of the project. Next to this the students should also take into account the existing information systems (for the course we only use 3 different SQL databases). Furthermore during this phase an information architecture should be developed and integration to the systems which are going to be reused needs to be accomplished. In the case both straight through processing and human interaction activities are used to integrate the order and delivery processes, students should be aware of this.

The students are expected to at least look at the various tables in each of the partner databases (such as product-, sales-, purchase- and production-tables and various other linked tables), and develop web services or applications that are able to:

- $\quad$ browse through the products (productid, name, price) of the retailer, wholesaler and manufacturer

- browse through the sales and purchase orders of the wholesaler (including order details)

- browse through the sales orders of the manufacturer (including order details)

- browse through the production orders of the manufacturer

- browse through the product stock levels (aggregated)

- $\quad$ provide information on ordered goods

- exchange information (such as order confirmations, delivery dates, updated stock levels)

- update customer information 
- update order information

- update product information (such as price, quantities)

In the final phase the proposed solution must be developed and implemented. The modeled processes should be executed by using the developed web services and applications. End-users should be able to start applications within their Internet browser and use them to start process activities. Also the identified key performance indicators should be implemented in order to monitor the operations in the supply chain. For this the students need to develop dashboards from which the performance indicators can easily be accessed by graphs, reports or performance meters.

At the end of the course each group of students that represents a supply chain are asked to present their solution. Processes are run by using the applications and several web services are checked (specifically does were the process does not seem to work correct or were students have made decisions regarding activities in a process that do not seem logical), finally the performance indicators are also checked. When the developed solution does not work properly it is often because one of the supply chain organizations has not delivered the correct web services or has an faulty integration to their backend systems. If this is the case the students that represent that specific organization are tested further on their level of knowledge and skills.

In the following section we discuss some of the outcomes and lessons learned during the five times that we have now run this course.

\section{Outcomes and Lessons Learned}

The course has run four complete cycles since 2006 (a fifth being taught as we write) and the amount of data for an evaluation is substantial. Over a 115 students have completed the course, of which around 34 were bachelor computer science students and 81 were graduate students business informatics. Yearly, the students evaluate the course through filling in a partly open and partly closed questionnaire. The overall conclusion is that the course is judged as being relevant (over the years scoring around 3.9 on a scale from 1 (lowest) - 5 (highest)). Each year the theoretical topics and the corresponding guest lectures are highly approved of, except for the odd guest lecture which is deemed too commercial, as e.g. a student complaints: "[...] a guest lecture in which the vendor's competitor is defined as incompetent should not be provided, and lacks an academic level [...]". Furthermore, there are some topics that students find less satisfying and that return more or less every year.

First and foremost the students find that cooperation between students of the two different universities, with the different types of education and levels, is difficult and time consuming. Within a short time of typically two months they are forced to learn to know each other and work together: "[...] it is so difficult to meet with my teammate: he has a different curriculum schedule. Moreover, the difference in level is also hard to cope with: I had to do a lot of work in writing the paper [...]". However, we deliberately take students out of their comfort zone and that experience is according to the evaluations not appreciated: in 2007, the students valued their collaboration with students from 'the other' university as 2.1 on a scale of 1 (lowest) -5 (highest). As 
this is part of the course design and it simulates real life projects we have decided not to change this aspect, but instead to work on a better facilitation for cooperation: in 2008 we 'forced' students to create teams immediately after the kick-off (during a drink provided by the university) instead of giving them a week time. A second finding from the evaluation is that students find the BPM-system, with which they have to work in the practical track, complex and far from easy. Because most of the students haven't worked with a BPM-system before they have to get to know the user interface and functionality of the application and be able to use it to build a supply chain solution all within 9 weeks. Especially if during the theoretical track we had a guest lecture from another BPMS vendor, students often asked us to use that other system. We feel however that they do not fully realize that the effort to know and master any system is complex and any system would cause learning difficulties; moreover, demo's of vendors of systems always provide a colored reality, which is different from the real experience.

A final issue which we receive during every evaluation is the complexity that comes with collaborating between the partners within a supply chain during the practical track. Students find that they really have to communicate and come to an agreement with all organizations in the supply chain on how the processes are going to be analyzed, what methods for process improvement are used, which information needs to be exchanged, and how to develop and publish web services. This is in accordance with the final results that we observe. Each year the supply chain that provides the best solution is the one which had thought out and agreed upon a clear architecture on all levels from process to application. Furthermore such a team typically uses the architecture to communicate about the projects progress. Whereas does that do not succeed in realizing optimized and integrated supply chain processes usually paid to much attention on only optimizing and automating their own organization without communicating with the other supply chain partners (i.e. they realize stovepipe solutions).

In short we can state that the students who participate in this course value it highly even though especially in the practical track they encounter a lot of issues and problems that make it difficult to fully accomplish the assignment.

Although every year there are areas of improvement and we continue to work on those, we are confirmed in our general approach through the years as multiple published scientific papers resulted from the theoretical part, and also more and more students now perform their final thesis project on the topic of BPM, having become enthusiastic after following the course.

From a scientific viewpoint, notably, the theoretical part of the BPM-course in 2007 provided us with enough material to write an overall paper on success factors of BPMS implementations using the material in papers that students provided [15]. Based on the material from the 2008 course too an overall paper has been published, this time on method fragments in BPMS implementation, again using the input from student papers [16]. In 2009, one of the papers from students was, with changes and additions by the teachers, submitted to the International Information Management Association (IIMA) conference, and elected as best paper [17]. In 2010 we have told our current batch of students that we intend to submit the best student contributions to the IIMA 2010 Student Consortium. 


\section{Conclusions and Future Outlook}

In conclusion, we state that the way in which the BPM course curriculum has been developed really enables students to not only acquire knowledge on BPM topics but to also attain skills that are highly valued by industry. By putting together students from different institutes and experience levels we simulate many of the 'soft' problems that people typically encounter in a real life BPM-systems implementation project.

Even though the BPM course can be considered a success there is a price we pay. Organizing the course is a major organizational effort for both universities involved. Each year, the timetables of both universities need to be synchronized for both students and lecturers, besides this arranging between 5 to 8 guest lectures takes a considerable amount of time. Also the effort needed to configure and maintain the BPM-system is substantial and finally students need a lot of energy for this course because they are taken out of their comfort zone and need to deal with a new and complex environment.

Based on the experiences of the last few years and the evaluations of the students we are continuously exploring possibilities to improve the course. One change is to make the group of students more equal. We will no longer combine groups of bachelor and master students of the two universities but we will offer this course to students who are following the bachelor business informatics. This means that there will be two different types of students in the course (more business oriented versus more technology oriented) but that they are on the same level of education. We expect that this will make the practical track of the course less complicated. Also this provides space at the master level of the business informatics education to provide a BPM advanced course that will focus completely on research in the BPM domain. Another change we are considering is the amount of involvement of business; currently this is limited to providing a number of guest lectures but we are thinking of having industry to submit small research projects that the students do as part of the course. This will further improve the practicality of the course. Finally we are continuously improving the amount of knowledge, support and information available on the BPM-system (Cordys) we use. Up till now we have used the Cordys C2 version of the application but with the currently running course we use Cordys BOP 4 and also the process factory which is a lighter version of the application that is offered as software as a service (SaaS). So while the domain of BPM is changing rapidly we aim to offer a course that is challenging and up-to-date and complies with the demands of our students, as well as science and industry.

\section{References}

1. Ravesteyn, P., Versendaal, J.M.: Constructing a Situation Sensitive Methodology for BPMS Implementation. In: 13th Pacific Asia Conference on Information Systems (2009)

2. Weske, M.: Business Process Management: Concepts, Languages, Architectures. Springer, New York (2007)

3. Hiemstra, A., Ravesteyn, P., Versendaal, J.M.: An Alignment Model for Business Process Management and Service Oriented Architecture. In: 6th International Conference on Enterprise Systems, Accounting and Logistics (2009) 
4. Seethamraju, R.: Enterprise Systems Software in Business School Curriculum - Evaluation of Design and Delivery. Journal of Information Systems Education 18 (2007)

5. Malekzadeh, A.R.: Diversity, integration, globalization and critical thinking in the upper division. Journal of Management Education 22, 590-603 (1998)

6. Ravesteyn, P., Batenburg, R., De Waal, B.: In Search of Competencies Needed in BPM Projects. Communications of the IIMA 8, 23-30 (2008)

7. Fingar, P.: The MBA is Dead, Long Live the MBI (2006), http: / / www. bptrends.com

8. Bandare, W., Rosemann, M., Davies, I., Tan, C.: A Structured Approach to Determining Appropriate Content for Emerging Information Systems Subjects: An Example for BPM Curricula Design. In: 18th Australasian Conference on Information Systems (2007)

9. Muehlen zur, M.: Class Notes: BPM Research and Education (2008), http: / / www. bptrends.com

10. Recker, J., Rosemann, M.: Teaching Business Process Modeling: Experiences and Recommendations. Communications of the Association for Information Systems 25, 379-394 (2009)

11. Hawking, P., McCarthy, B., Stein, A.: Integrating ERP's Second Wave into Higher Education Curriculum. In: 9th Pacific Asia Conference on Information Systems (2005)

12. Jensen, T., Fink, J., Moller, C., Rikhardsson, P., Kraemmergaard, P.: Issues in ERP Education Development - Evaluation of the Options Using Three Different Models. In: ICESAcc Proceedings (2005)

13. McGaughey, R.E., Gunasekaran, A.: Enterprise Resource Planning (ERP): Past, Present and Future. International Journal of Enterprise Information Systems 4, 23-35 (2008)

14. Cordys, http: / / www. cordys. com

15. Ravesteyn, P., Versendaal, J.M.: Success Factors of Business Process Management Systems Implementation. In: 18th Australasian Conference on Information Systems (2007)

16. Ravesteyn, P., Jansen, S.: A Situational Implementation Method for Business Process Management Systems. In: 15th Americas Conference on Information Systems (2009)

17. Kristjansson, B., Mikalef, P., Versendaal, J.M., Ravesteyn, P.: Applying Human Interaction Management Concepts to E-Mailing: A Visualized Conceptual Model. Communications of the International Information Management Association 9 (2009) 